\title{
VENTAJAS DEL USO DEL PRESERVATIVO, LA PÍLDORA ANTICONCEPTIVA Y LA PÍLDORA POSTCOITAL SEGÚN LOS JÓVENES
}

\author{
Gómez, A. B. \\ Planes, M. \\ montserrat.planes@udg.edu \\ Gras, M. E. \\ Instituto de Investigación sobre Calidad de Vida \\ Universidad de Girona
}

Fecha de Recepción: 3 Marzo 2018

Fecha de Admisión: 10 Abril 2018

\section{RESUMEN}

Se comparan tres métodos sexuales preventivos según las ventajas que proporciona su uso. Participan en el estudio 140 jóvenes estudiantes de grado (77.1\% mujeres; edad media 20.7; $\mathrm{dt}=3.1$ ). Se pide a los jóvenes que ordenen cuantitativamente cada uno de estos métodos utilizando una escala ipsativa. El preservativo es valorado principalmente como protector de la salud sexual y por su carencia de efectos secundarios. El método más valorado para incrementar la sensación de placer en el hombre y la mujer es la píldora anticonceptiva seguida de la píldora postcoital. Globalmente el método mejor valorado es el preservativo y el menos valorado la píldora postcoital.

Palabras clave: preservativo; píldora anticonceptiva; píldora postcoital

\section{ABSTRACT}

Advantages of condom use, contraceptive pill and postcoital pill according to young people.

Three preventive sexual methods are compared according to the advantages they provide. 140 young undergraduate students participate in the study $(77.1 \%$ women, mean age $20.7, \mathrm{dt}=3.1)$. Young people are requested to quantitatively order these methods using an ipsative scale. The condom is valued mainly as a protector of sexual health and for the lack of side effects. The most valued method for increasing men and women's pleasure sensation is the contraceptive pill, followed by the postcoital pill. Globally, the most and the least valued methods are the condom and the postcoital pill, respectively.

Keywords: condom; contraceptive pill; postcoital pill

\section{ANTECEDENTES:}

El Estudio poblacional sobre el uso y la opinión de los métodos anticonceptivos en España (Sociedad Española de Contracepción, 2016) señala al preservativo y a la píldora anticonceptiva 
como los métodos más utilizados por las jóvenes españolas de 15 a 24 años. Así mismo, el preservativo, la píldora anticonceptiva y la píldora postcoital, juntamente con el coitus interruptus, fueron los métodos más utilizados para evitar los embarazos no deseados que comunicaron 583 jóvenes españolas de 13 a 24 años, en un centro de salud en Zaragoza (Yago y Tomas, 2014). Además, de su eficacia como anticonceptivo, el preservativo también protege de las infecciones de transmisión sexual (UNAIDS, 2016), objetivo que no cumplen los restantes métodos. Sin embargo, aunque la tasa de uso del preservativo ha ido creciendo en los últimos años entre los jóvenes, muchos de ellos todavía se ponen en riesgo frente a una ITS o a un embarazo no deseado por no emplearlo sistemáticamente (Grimley, Prochaska, Velicer y Prochaska, 1995; Prat, Planes, Gras y Sullman, 2016; Tschann, Flores, de Groat, Deardorff y Wibbeisman, 2010).

Diversos modelos preventivos como el de Creencias de salud, el Transteórico de las etapas de cambio y la Teoría del balance decisional, entre otros, han puesto de manifiesto que la realización de conductas protectoras depende del peso relativo de los beneficios que se pueden obtener con ellas, si se comparan con las molestias o dificultades que supone su adopción (Grimley et al., 1995; Janis y Mann, 1977; Maiman y Becker, 1974 ). Por lo tanto, averiguar el orden de preferencia y el peso relativo que otorgan los jóvenes a las ventajas de los diferentes métodos de protección sexual, puede dar una idea de la probabilidad con que van a utilizarlos.

\section{OBJETIVO}

El objetivo de este trabajo es comparar las valoraciones de los jóvenes sobre las ventajas de tres métodos de prevención sexual, como son el preservativo, la píldora anticonceptiva y la píldora postcoital, por lo que se refiere a la protección de la salud sexual, el incremento de la sensación de placer, la facilidad de uso, la accesibilidad económica y la tranquilidad durante y después de la relación sexual.

\section{PARTICIPANTES}

Participan en el estudio 140 estudiantes del grado de Psicología de la Universidad de Girona, de los cuales un $77.1 \%$ son mujeres y el $64.14 \%$ menores de 21 años ( $m e d i a$ de edad= 20.7, $d t=3.1$ )

\section{INSTRUMENTO}

Se empleó un listado de 10 ítems extraídos del Cuestionario de ventajas e inconvenientes del uso del preservativo con una pareja afectiva heterosexual (CIVIUP) de Planes, Prat, Gómez, Gras y Font-Mayolas (2012) adaptado a los objetivos del presente estudio.

Se pidió a los participantes que evaluaran cuantitativamente cada uno de los tres métodos (preservativo, píldora anticonceptiva y píldora postcoital) utilizando una escala ipsativa. Las instrucciones que se daban eran las siguientes: debes repartir 100 puntos entre el preservativo, la píldora anticonceptiva y la píldora postcoital ("según protejan de la infecciones de transmisión sexual", "según sean de accesibles económicamente", etc.), no puedes otorgar el mismo valor a dos métodos ni puedes dar valor cero a ninguno de ellos. Con estas instrucciones se pretendía conocer la preferencia, por pequeña que fuera, de un método sobre los demás.

\section{PROCEDIMIENTO}

La información se recogió al final de la clase de una asignatura obligatoria previa autorización del profesor responsable y consentimiento de los estudiantes. Se garantizó el anonimato y la confidencialidad de las respuestas y el uso de los resultados solo con fines de investigación. 


\section{ANÁLISIS DE DATOS}

Los datos se analizaron con el paquete estadístico SPSS V.23. Se calcularon medias y desviaciones estándar de las puntuaciones de los diferentes ítems.

\section{RESULTADOS}

Las medias y desviaciones típicas de las puntuaciones otorgadas a cada ítem según el método evaluado se presentan en la tabla 1.

Tabla 1.

Medias y desviaciones típicas de las puntuaciones otorgadas a cada método según la ventaja evaluada.

\begin{tabular}{l|c|c|c}
\hline Ventaja & $\begin{array}{c}\text { Preservativo } \\
\text { Media (dt) }\end{array}$ & $\begin{array}{c}\text { Píldora } \\
\text { anticonceptiva } \\
\text { Media(dt) }\end{array}$ & $\begin{array}{c}\text { Píldora } \\
\text { postcoital } \\
\text { Media (dt) }\end{array}$ \\
\hline Evita la transmisión del virus del sida & $\mathbf{9 1 . 3 6 ( 1 0 . 3 4 )}$ & $\mathbf{5 . 5 6}(\mathbf{7 . 0 8 )}$ & $\mathbf{2 . 9 9 ( 3 . 2 0 )}$ \\
\hline Evita las infecciones de transmisión sexual & $\mathbf{8 7 . 5 1 ( \mathbf { 1 3 . 6 4 } )}$ & $\mathbf{7 . 9 2}(\mathbf{9 . 6 9 )}$ & $\mathbf{4 . 4 2}(\mathbf{5 . 1 1})$ \\
\hline No provoca efectos secundarios & $77.06(27.55)$ & $12.07(14.25)$ & $10.36(17.64)$ \\
\hline Muestra interés por proteger la salud de la pareja & $76.66(20.82)$ & $17.70(18.21)$ & $5.41(5.70)$ \\
\hline Es accesible económicamente & $53.06(24.05)$ & $29.81(20.07)$ & $17.33(18.36)$ \\
\hline Da tranquilidad durante y después de la relación & $47.19(22.14)$ & $43.55(21.86)$ & $9.15(9.08)$ \\
\hline Previene un embarazo no deseado & $46.73(18.86)$ & $39.50(17.47)$ & $13.77(12.92)$ \\
\hline Es fácil de usar & $42.25(24.25)$ & $37.38(21.73)$ & $20.83(18.18)$ \\
\hline Incrementa las sensaciones de placer de la mujer & $\mathbf{1 4 . 7 6 ( 1 4 . 4 6 )}$ & $\mathbf{6 0 . 4 4}(\mathbf{2 2 . 4 4 )}$ & $\mathbf{2 4 . 7 6 ( 2 0 . 5 7 )}$ \\
\hline Incrementa las sensaciones de placer del hombre & $\mathbf{1 2 . 3 6 ( 1 4 . 1 8 )}$ & $\mathbf{6 0 . 9 7 ( 2 2 . 1 3 )}$ & $\mathbf{2 6 . 6 3 ( \mathbf { 1 9 . 9 5 } )}$
\end{tabular}

El preservativo es el método que se considera más ventajoso en todos los casos excepto por lo que se refiere al incremento de las sensaciones de placer del hombre y de la mujer. En cuanto a las ventajas relacionadas con la protección de la salud sexual (evita la transmisión del virus de la sida y las infecciones de transmisión sexual, no provoca efectos secundarios y muestra interés por proteger la salud de la pareja) el preservativo obtiene puntuaciones destacadamente más elevadas en comparación con los otros dos métodos. También es muy valorado por lo que se refiere a la accesibilidad económica.

Aunque el uso del preservativo sigue siendo el método más valorado por la tranquilidad que da durante y después de la relación, como preventivo de embarazos no deseados y por su facilidad de uso, la píldora anticonceptiva obtiene puntuaciones no muy inferiores.

La píldora anticonceptiva es el método más valorado para incrementar las sensaciones de placer del hombre y de la mujer, seguido de la píldora postcoital.

La píldora postcoital es el método peor valorado en todos los casos. 


\section{DISCUSIÓN}

La metodología de evaluación empleada en este estudio ha permitido conocer las preferencias de los participantes en relación al preservativo, la píldora anticonceptiva y la píldora postcoital según diez posibles ventajas. Pero además de ordenarlas les ha otorgado un peso relativo que complementa dicha información. Por ejemplo no es lo mismo el primer lugar que ocupa el preservativo en tanto que protector frente a la transmisión del virus del sida, que por su facilidad de uso: en el primer caso su puntuación media es del 91.76 mientras que en el segundo es de 42.25, no muy lejos del 37.38 que obtiene la píldora anticonceptiva.

En investigaciones previas se ha comprobado que cuando las ventajas que ofrece el condón como método preventivo superan los inconvenientes que también pueda presentar, su probabilidad de uso se incrementa (Grimley et al., 1995; Planes et al., 2012; Prat et al., 2016). Seguramente ocurra lo mismo cuando un joven tiene que elegir entre varios métodos disponibles: se inclinará preferentemente por aquel que le ofrezca más ventajas y menos inconvenientes. Si consideramos las puntuaciones altas como ventajas y las bajas como inconvenientes, el preservativo seria el método preferido.

Además, las valoraciones elevadas obtenidas por el preservativo respecto a su falta de efectos secundarios y a que proporciona tranquilidad durante y después de la relación sexual son de gran interés, si se tiene en cuenta que la primera variable han resultado predictiva del uso sistemático del preservativo en las mujeres y la segunda de la misma conducta en los hombres (Prat et al., 2016). Así mismo, en el estudio citado se observó que la percepción de las mujeres de que disminuye el placer sexual de la mujer, fue la variable que significativamente explicó el menor uso del preservativo en este colectivo.

Las preguntas de respuesta forzada tienen la ventaja de minimizar el sesgo de deseabilidad social (Calderón y Ximénez, 2014) inherente al uso de autoinformes con escalas tipo Likert y por tanto permiten conocer mejor las preferencias de los participantes. Sin embargo, este estudio tiene una serie de limitaciones. En primer lugar al haberse recogido los datos con una escala ipsativa, éstos no se pueden analizar más a fondo con las técnicas estadísticas tradicionales y por ello en este trabajo únicamente se presentan los resultados descriptivos. Por otra parte, la muestra de conveniencia no permite la generalización de los resultados a colectivos más amplios de jóvenes.

\section{CONCLUSIONES}

En general, las valoraciones de los diferentes métodos apuntan a un reconocimiento del preservativo como el más ventajoso de los tres en casi todas las dimensiones examinadas. Sin embargo también se detectan algunos puntos débiles que podrían perjudicar su uso.

Convendría, por tanto, que en los programas preventivos se destacaran las ventajas más notables del uso del preservativo y se intentaran mejorar las bajas valoraciones del mismo sobre su capacidad para incrementar las sensaciones de placer. Una posible vía para lograrlo sería argumentar que, cuando una persona se siente tranquila y sin preocupaciones sobre los posibles riesgos para su salud porque se considera bien protegida, está en mejores condiciones para disfrutar del sexo con plenitud.

\section{REFERENCIAS}

Calderon, C. y Ximénez, C. (2014). Análisis factorial de ítems de respuesta forzada: una revisión y un ejemplo. Revista Latinoamericana de psicología, 46 (1), 24-34.

Grimley, D. M., Prochaska, J.0. , Velicer, W. F. and Prochaska, G. E. (1995) Contraceptive and condom use adoption and maintenance: a stage paradigm approach. Health Education Quarterly, 22, 20-35. 
Janis, I. L. y Mann, L. (1977). Decision making: A psychological analysis of conflict, choice, and commitment. New York, NY, US: Free Press.

Maiman, L.A. y Becker, M.H. (1974). The health belief model: Origins and correlates in psychological theory. Health Education Monographs, 2, 336-353.

Planes, M., Prat, F.X, Gómez, A.B., Gras, M.E. i Font-Mayolas, S. (2012). Ventajas e inconvenientes del uso del preservativo con una pareja afectiva heterosexual. Anales de Psicología, 28 (1), 161170.

Prat, F., Planes, M., Gras, M.E. i Sullman, M.J.M. (2016). Perceived pros and cons of condom use as predictors of its consistent use with a heterosexual romantic partner among young adults. Current Psychology, 35, 13-21.

Sociedad Española de Contracepción (2016). Estudio poblacional sobre el uso y la opinión de los métodos anticonceptivos en España. Recuperado el 20 de marzo de 2018 de http://www.hosting.sec.es/descargas/OBS_EncuestaAnticoncepcion2016.pdf.

Tschann, J.M., Flores, E., de Groat, C.L, Deardorff, J. y Wibbeisman, Ch.J. (2010). Condom negotiation strategies and actual condom use among latino youth. Journal of Adolescent Health, 47 (3), 254-262.

UNAIDS (2016). Condoms. Recuperado el 21 de marzo de 2018 de http://www.unaids.resources/presscentre/.../20161002_condoms.

Yago, T. y Tomas, C. (2014). Variables sociodemográficas relacionadas con embarazos no planificados en jóvenes de 13 a 24 años. Revista Española de Salud Pública, 88 (3), 395-406. 
